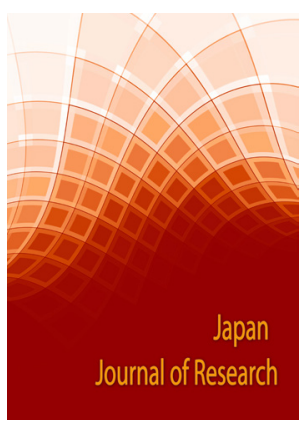

Correspondence

Masakazu Ishii, Ph.D

Division of Physiology and Pathology, Faculty of Pharmaceutical Sciences, Teikyo Heisei University, 4-21-2 Nakano, Nakano-ku, Tokyo 164-8530, Japan

Tel: +81-3-5860-4038

Email: masakazu.ishii@thu.ac.jp

- Received Date: 26 Jan 2020;

- Accepted Date: 04 Feb 2020;

- Publication Date: 08 Feb 2020.

Copyright

(c) 2020 Science Excel. This is an openaccess article distributed under the terms of the Creative Commons Attribution 4.0 International license.

\title{
Relationship between migraine and internet addiction in pharmacy students
}

\author{
Masakazu Ishii ${ }^{12^{*}}$, Hirotaka Katoh ${ }^{3,4}$, Hideyo Kasai ${ }^{4}$ and Masaaki Ishibashi ${ }^{1,2}$ \\ 'Division of Physiology and Pathology, Faculty of Pharmaceutical Sciences, Teikyo Heisei University, Tokyo, Japan \\ ${ }^{2}$ Division of Physiology and Pathology, Showa University School of Pharmacy, Tokyo, Japan \\ ${ }^{3}$ Kuramae Kato Medical Clinic, Tokyo, Japan \\ ${ }^{4}$ Department of Neurology, Showa University School of Medicine, Tokyo, Japan
}

\begin{abstract}
Background: In recent years, with the rapid popularization of the Internet, lifestyle disturbances, such as insufficient sleep due to excessive use of the Internet, is of concern. Sleep problems are known to trigger migraines. To clarify the relationship between migraine and Internet addiction, a questionnaire survey was conducted for pharmacy students at university.

Methods: Internet addiction symptoms were assessed using the Internet Addiction Test (IAT), and migraine was evaluated using modified Japanese migraine screening. Continuous variables were analysed using the unpaired Student's t-test or one-way analysis of variance followed by multiple Turkey's comparison tests. Categorical variables were analysed by the $x^{2}$ test.

Results: The recovery rate was $98.9 \%$ (442 / 447 students). Of the 288 students who had headaches in the past 3 months, 145 students (32.8\%, 145/442 students) were judged as having migraines by migraine screening. Sleep problems (62.1\%) were observed in the migraine group. Moreover, sleep deprivation due to headache was noted in $31.7 \%$ of the migraine group. The percentage of students with Internet addiction in the migraine group was significantly higher than that in the other headache group or no headache group.

Conclusions: Internet addiction was associated with the presence/absence of migraine in pharmacy students at university.
\end{abstract}

\section{Introduction}

Migraine is a common neurological disorder that is typically characterized by severe pain on one or both sides of the head and disturbances in vision. During migraine attacks, patients often develop nausea/vomiting, and increased sensitivity to their surroundings, including light (photophobia), sound (phonophobia) and odors (osmophobia) $[1,2]$. In Japan, the prevalence of migraine is $8.4 \%$ of the population, and is especially high in those aged 20 to 40 [3]. In our previous study on pharmacy students, the prevalence of migraine was $28.3 \%$, and the prevalence among female students was $30.9 \%$. Compared with the prevalence of $12.9 \%$ of women in their 20s reported in the epidemiological survey in Japan [3], the prevalence in pharmacy students is much higher. Moreover, headaches affect daily life $(50.0 \%)$ and studies (48.2\%) in students with migraine [4]. In addition, the triggers of migraine attacks were sleep deprivation and excessive sleep (58.2\%) [4].

In recent years, with the rapid popularization of the Internet, lifestyle disturbances, such as insufficient sleep due to excessive use of the Internet, is of concern [5]. Katayama and MizunoMatsumoto reported that $58 \%$ of university students were Internet-dependent, and students with Internet dependency have trouble sleeping, which causes physical and mental health problems [6]. Stress, irregular diet and sleep problems are known triggers of migraine [1-3,7]. Moreover, we previously suggested depression to be involved in the aggravation of migraine [7]. In addition, Ha et al. reported that Internet addiction (IA) is associated with depressive symptoms [8]. Thus, lack of sleep due to excess use of the Internet may be involved in the development of migraines. However, Cerutti et al. reported that IA is not associated with headache or type of headache [9]. Therefore, in this study, a questionnaire survey was conducted for pharmacy students at university to clarify the relationship between migraine and IA.

\section{Methods}

\section{Subjects}

A questionnaire survey was conducted between December 2017 and March 2018 for pharmacy students at the Showa University School of Pharmacy (447 students). To protect the respondent's personal information, the questionnaire was anonymous. This study was approved by the Institutional Ethics Committee of Showa University (Approval No. 298).

\section{Questionnaire study}

Data on the effects of headache on sleep, study and daily life, and triggers of headache were collected using a questionnaire. 
To select students with migraine, we used the modified ID migraine screener Japanese version [4], which included five items: headache exacerbation during daily activities, nausea, photophobia, osmophobia and phonophobia, covering the past 3 months. Based on previous study by Lipton et al., [10] we assessed headache exacerbation during daily activities, nausea, photophobia, osmophobia and phonophobia using the following criteria: "yes" assigned to response of "less than half the time" or "half the time or more". Participants who answered yes to at least two of five questions were considered to have migraines. Of the students who had headaches in the past 3 months, those who did not meet the criteria of migraine were considered to have other headaches. Moreover, students with migraines who answered yes to the question about aura symptoms (visual symptom) were considered to have migraine with aura. In this way, migraine was evaluated according to the International Classification of Headache Disorders, Third Edition beta version (ICHD-3 beta) [11].

Internet addiction (IA) was first proposed by Young in 1998 [12]. All subjects are divided into non-IA, possible IA or IA in increasing order of problem severity related to Internet usage according to Young's Internet Addiction Test (YIAT). The YIAT is a 20-item questionnaire, with a total score ranging from 20 to 100 . A higher total score indicates greater IA. Respondents were classified according to their total YIAT scores: $\geq 70$ as IA; $40-69$ as possible IA; and $20-39$ as non-IA. In this study, Internet use means personal computer, mobile phone or online game use. In addition, we also collected information on Internet use time, usage before bedtime and purpose of using the Internet.

\section{Statistical analysis}

Continuous variables were analysed using the unpaired Student's t-test or one-way analysis of variance followed by multiple Turkey's comparison tests. Values of $\mathrm{P}<0.05$ were considered significant. Categorical variables were analysed by the $\chi^{2}$ test using Excel Statistics (Excel Toukei) 2008 for Windows (Social Survey Research Information Co., Tokyo, Japan). Values of $\mathrm{P}<0.05$ were considered significant for analyses between two groups, and critical value of $\mathrm{P}<0.017$ was considered significant $(\mathrm{P}=0.05 / 3$ woodlands) for analyses among three groups.

\section{Results}

\section{Background of respondents}

The recovery rate was $98.9 \%$ ( $442 / 447$ students). Of the 288 students who had headaches in the past 3 months, 145 were judged as having migraine by migraine screening, and the prevalence rate was $32.8 \%$ (145/442 students, Table 1). The average age of the respondents was $21.4 \pm 2.0$ years for the migraine group, $21.6 \pm 1.9$ years for the other headache group and $21.0 \pm 2.0$ years for the no headache group (Table 1). There were 129 women (89.0\%) in the migraine group, 105 women (73.4\%) in the other headache group and 117 women (76.0\%) in the no headache group (Table 1). The proportion of females in the migraine group was significantly higher than that in the other groups (Table 1).

\section{Accompanying symptoms of headache and aura symptoms}

The amount of days per month with headache was $4.4 \pm 4.5$ days $/$ month in the migraine group, and $2.8 \pm 2.9$ days/month in the other headache groups ( $\mathrm{p}<0.001$, Table 2 ). The headache onset time was not different between the migraine group and other headache groups (Table 2). In the migraine group, headache exacerbation during daily activities and accompanying symptoms, such as nausea, photophobia, osmophobia and phonophobia, were noted in $81.4 \%, 45.5 \%, 49.7 \%, 37.3 \%$ and $70.4 \%$, respectively (Table 2 ). In the migraine group, $18.6 \%$ (27 students / 145 students) had migraine with aura (Table 2).

\section{Influence of headache on daily life and triggers of headaches}

Students in the migraine group (31.7\%) and students in the other headache group (11.2\%) had sleep deprivation due to headache (Table 3). Approximately $35.9 \%$ of the students with migraines responded that migraines influenced their daily life and learning (Table 3). Triggers of headache, including strong light, smells, crowds, temperature difference, food, weather and atmospheric pressure, were significantly more frequent in the migraine group (Table 3 ). The number of students who did not know what triggered their headaches was significantly higher in the other headache group than in the migraine group (Table $3)$.

\begin{tabular}{|c|c|c|c|c|c|c|c|c|c|}
\hline & \multicolumn{2}{|c|}{$\overline{\text { Migraine }}$} & \multicolumn{2}{|c|}{ Other headache } & \multirow[t]{2}{*}{ p-value ${ }^{(1)}$} & \multicolumn{2}{|c|}{ No headache } & \multirow[t]{2}{*}{ p-value $e^{(2)}$} & \multirow[t]{2}{*}{ p-value ${ }^{(3)}$} \\
\hline & $n=145$ & $\%$ & $n=143$ & $\%$ & & $\mathrm{n}=154$ & $\%$ & & \\
\hline Age $($ mean $\pm \mathrm{SD})$ & \multicolumn{2}{|c|}{$21.4 \pm 2.0$} & \multicolumn{2}{|c|}{$21.6 \pm 1.9$} & 0.685 & \multicolumn{2}{|c|}{$21.0 \pm 2.0$} & 0.289 & 0.051 \\
\hline \multicolumn{10}{|l|}{ Sex } \\
\hline Male & 16 & 11.0 & 38 & 26.6 & $<0.001^{*}$ & 37 & 24.0 & $0.003 *$ & 0.614 \\
\hline Female & 129 & 89.0 & 105 & 73.4 & & 117 & 76.0 & & \\
\hline \multicolumn{10}{|l|}{ Frequency of headache } \\
\hline Often & 68 & 46.9 & 34 & 23.8 & $<0.001^{*}$ & 4 & 2.6 & $(-)$ & $(-)$ \\
\hline Sometimes & 69 & 47.6 & 91 & 63.6 & & 59 & 38.3 & & \\
\hline Rarely & 7 & 4.8 & 17 & 11.9 & & 77 & 50 & & \\
\hline None & 0 & 0 & 1 & 0.7 & & 14 & 9.1 & & \\
\hline No response & 1 & 0.7 & 0 & 0 & & 0 & 0 & & \\
\hline \multicolumn{10}{|c|}{$\begin{array}{l}\text { Headache within the past } 3 \\
\text { months }\end{array}$} \\
\hline Yes & 145 & 100 & 143 & 100 & & 0 & 0 & & $(-)$ \\
\hline No & 0 & 0 & 0 & 0 & $(-)$ & 154 & 100 & $(-)$ & $(-)$ \\
\hline
\end{tabular}

\footnotetext{
*:p<0.017(0.05/3)
}

${ }^{(1)}$ Migraine vs Other headache, ${ }^{(2)}$ Migraine vs No headache, ${ }^{(3)}$ Other headache vs No headache 
Internet addiction and purpose of use of the Internet

The IA score in the migraine group was significantly higher than that in the other headache group or no headache group (Table 4). However, the usage time of the Internet and Internet usage at bedtime were not different among the groups (Table 4). As for the purpose of Internet use, replying to emails and LINE communication was the most common in all groups (Table 4 ).

\begin{tabular}{|c|c|c|c|c|}
\hline & \multicolumn{2}{|c|}{ Migraine } & \multicolumn{2}{|c|}{ Other headache } \\
\hline & $n=145$ & $\%$ & $\mathrm{n}=143$ & $\%$ \\
\hline Frequency of headache (days/month, mean \pm SD) & \multicolumn{2}{|c|}{$4.4 \pm 4.5$} & \multicolumn{2}{|c|}{$2.8 \pm 2.9$} \\
\hline NS & 1 & & 3 & \\
\hline \multicolumn{5}{|l|}{ Headache onset time } \\
\hline Upon waking & 12 & 8.3 & 13 & 9.1 \\
\hline In the morning & 3 & 2.1 & 6 & 4.2 \\
\hline Afternoon & 45 & 31.0 & 36 & 25.2 \\
\hline Before bedtime & 0 & 0 & 1 & 0.7 \\
\hline Undecided & 78 & 53.8 & 78 & 54.5 \\
\hline Other & 7 & 4.8 & 9 & 6.3 \\
\hline \multicolumn{5}{|l|}{ Headache exacerbation during daily activities } \\
\hline Never & 10 & 6.9 & 57 & 39.9 \\
\hline Rarely & 16 & 11.0 & 43 & 30.1 \\
\hline Less than half the time & 72 & 49.7 & 29 & 20.3 \\
\hline Half the time or more & 46 & 31.7 & 13 & 9.1 \\
\hline No response & 1 & 0.7 & 1 & 0.7 \\
\hline \multicolumn{5}{|l|}{ Nausea } \\
\hline Never & 40 & 27.6 & 110 & 76.9 \\
\hline Rarely & 39 & 26.9 & 24 & 16.8 \\
\hline Less than half the time & 44 & 30.3 & 8 & 5.6 \\
\hline Half the time or more & 22 & 15.2 & 1 & 0.7 \\
\hline \multicolumn{5}{|l|}{ Photophobia } \\
\hline Never & 51 & 35.2 & 118 & 82.5 \\
\hline Rarely & 22 & 15.2 & 20 & 14.0 \\
\hline Less than half the time & 49 & 33.8 & 4 & 2.8 \\
\hline Half the time or more & 23 & 15.9 & 1 & 0.7 \\
\hline \multicolumn{5}{|l|}{ Osmophobia } \\
\hline Never & 64 & 44.1 & 130 & 90.9 \\
\hline Rarely & 27 & 18.6 & 11 & 7.7 \\
\hline Less than half the time & 33 & 22.8 & 2 & 1.4 \\
\hline Half the time or more & 21 & 14.5 & 0 & 0 \\
\hline \multicolumn{5}{|l|}{ Phonophobia } \\
\hline Never & 24 & 16.6 & 104 & 72.7 \\
\hline Rarely & 19 & 13.1 & 29 & 20.3 \\
\hline Less than half the time & 69 & 47.6 & 10 & 7.0 \\
\hline Half the time or more & 33 & 22.8 & 0 & 0 \\
\hline \multicolumn{5}{|c|}{ Visual aura (flickering lights, spots or lines, and loss of vision) } \\
\hline Never & 101 & 69.7 & 128 & 89.5 \\
\hline Rarely & 17 & 11.7 & 8 & 5.6 \\
\hline Less than half the time & 21 & 14.5 & 7 & 4.9 \\
\hline Half the time or more & 6 & 4.1 & 0 & 0 \\
\hline \multicolumn{5}{|l|}{ Type of migraine } \\
\hline MA & 27 & 18.6 & \multirow{2}{*}{\multicolumn{2}{|c|}{$(-)$}} \\
\hline MO & 118 & 81.4 & & \\
\hline
\end{tabular}

NS: not specified,

MA: migraine with aura; MO: migraine without aura 


\begin{tabular}{|c|c|c|c|c|c|}
\hline & \multicolumn{2}{|c|}{ Migraine } & \multicolumn{2}{|c|}{ Other headache } & \multirow[t]{2}{*}{ p-value } \\
\hline & $n=145$ & $\%$ & $n=143$ & $\%$ & \\
\hline \multicolumn{6}{|l|}{ Sleep deprivation due to headache } \\
\hline Never & 64 & 44.1 & 103 & 72.0 & \\
\hline Rarely & 34 & 23.4 & 24 & 16.8 & \\
\hline Less than half the time & 38 & 26.2 & 13 & 9.1 & $<0.001 *$ \\
\hline Half the time or more & 8 & 5.5 & 3 & 2.1 & \\
\hline No response & 1 & 0.7 & 0 & 0 & \\
\hline \multicolumn{6}{|l|}{ Influence of headache on daily life } \\
\hline Stay in bed & 28 & 19.3 & 3 & $\begin{array}{l}2.1 \\
4.9\end{array}$ & \\
\hline Considerably hindrance (excluding sleep) & 24 & 16.6 & 7 & $\begin{array}{r}4.9 \\
58.7\end{array}$ & \\
\hline Somewhat affected (excluding sleep) & 81 & 55.9 & 84 & $\begin{array}{l}58.1 \\
34.3\end{array}$ & $<0.001^{*}$ \\
\hline No influence & 11 & 7.6 & 49 & $\begin{array}{r}34.3 \\
0\end{array}$ & \\
\hline No response & 1 & 0.7 & 0 & 0 & \\
\hline \multicolumn{6}{|l|}{ Influence of headache on learning } \\
\hline Unable to study & 22 & 15.2 & 8 & 5.6 & \\
\hline Ability is halved & 30 & 20.7 & 15 & 10.5 & \\
\hline A little effect & 73 & 50.3 & 67 & 46.9 & $<0.001 *$ \\
\hline No influence & 18 & 12.4 & 53 & 37.1 & \\
\hline No response & 2 & 1.4 & 0 & 0 & \\
\hline \multicolumn{6}{|l|}{ Triggers of headache (multiple answers allowed) } \\
\hline Stress & 82 & 56.6 & 76 & 53.1 & 0.562 \\
\hline Menstruation (only for females) & 59 & 40.7 & 38 & 26.6 & 0.140 \\
\hline Sleep deprivation / excessive sleep & 90 & 62.1 & 80 & 55.9 & 0.291 \\
\hline Disturbance of eating habits & 10 & 6.9 & 10 & 7.0 & 0.974 \\
\hline Strong light & 21 & 14.5 & 4 & 2.8 & $<0.001 *$ \\
\hline Smell & 33 & 22.8 & 6 & 4.2 & $<0.001^{*}$ \\
\hline Crowds & 47 & 32.4 & 15 & 10.5 & $<0.001 *$ \\
\hline Temperature difference & 36 & 24.8 & 21 & 14.7 & $0.031 *$ \\
\hline Food & 7 & 4.8 & 1 & 0.7 & 0.067 \\
\hline Weather, atmospheric pressure & 72 & 49.7 & 50 & 35.0 & $0.012 *$ \\
\hline Unknown & 11 & 7.6 & 25 & 17.5 & $0.011^{*}$ \\
\hline Others & 23 & 15.9 & 18 & 12.6 & \\
\hline
\end{tabular}

Migraine vs Other headache

Table 3. Influence of headache on daily life and triggers of headaches

\begin{tabular}{|c|c|c|c|c|c|c|c|c|c|}
\hline & \multicolumn{2}{|c|}{ Migraine } & \multicolumn{2}{|c|}{ Other headache } & \multirow{2}{*}{ p-value $e^{(1)}$} & \multicolumn{2}{|c|}{ No headache } & \multirow{2}{*}{ p-value ${ }^{(2)}$} & \multirow{2}{*}{ p-value $e^{(3)}$} \\
\hline & $n=145$ & $\%$ & $n=143$ & $\%$ & & $n=154$ & $\%$ & & \\
\hline \multicolumn{10}{|l|}{ Internet addiction } \\
\hline IA (70-100 score) & 11 & 7.6 & 2 & 1.4 & $0.006^{*}$ & 2 & 1.3 & $0.001 *$ & 0.892 \\
\hline Possible IA (40-69 score) & 77 & 53.1 & 66 & 46.2 & & 68 & 44.2 & & \\
\hline No IA (20-39 score) & 53 & 36.6 & 73 & 51.0 & & 84 & 54.5 & & \\
\hline No response & 4 & 2.8 & 2 & 1.4 & & 0 & 0 & & \\
\hline Score $($ mean $\pm \mathrm{SD})$ & \multicolumn{2}{|c|}{$45.2 \pm 14.3$} & \multicolumn{2}{|c|}{$41.8 \pm 11.9$} & $0.048^{*}$ & \multicolumn{2}{|c|}{$39.7 \pm 10.4$} & $<0.001 *$ & 0.306 \\
\hline No response & 4 & 2.8 & 2 & 1.4 & & 0 & 0 & & \\
\hline \multicolumn{10}{|l|}{ Usage time per day } \\
\hline Weekday (hour, mean \pm SD) & \multicolumn{2}{|c|}{$3.4 \pm 1.8$} & \multicolumn{2}{|c|}{$3.2 \pm 2.0$} & 0.849 & \multicolumn{2}{|c|}{$3.1 \pm 2.3$} & 0.433 & 0.774 \\
\hline No response & 10 & 6.9 & 5 & 3.5 & & 5 & 3.2 & & \\
\hline Weekend (hour, mean \pm SD) & \multicolumn{2}{|c|}{$4.6 \pm 2.5$} & \multicolumn{2}{|c|}{$4.5 \pm 2.8$} & 0.940 & \multicolumn{2}{|c|}{$4.1 \pm 2.7$} & 0.190 & 0.335 \\
\hline No response & 10 & 6.9 & 5 & 3.5 & & 5 & 3.2 & & \\
\hline Before bedtime use (hour, mean \pm SD) & \multicolumn{2}{|c|}{$0.4 \pm 2.1$} & \multicolumn{2}{|c|}{$0.2 \pm 0.5$} & 0.374 & \multicolumn{2}{|c|}{$0.3 \pm 1.0$} & 0.871 & 0.661 \\
\hline No response & 7 & 4.8 & 5 & 3.5 & & 4 & 2.6 & & \\
\hline
\end{tabular}




\begin{tabular}{|c|c|c|c|c|c|c|c|c|c|}
\hline & \multicolumn{2}{|c|}{ Migraine } & \multicolumn{2}{|c|}{ Other headache } & \multirow{2}{*}{ p-value ${ }^{(1)}$} & \multicolumn{2}{|c|}{ No headache } & \multirow{2}{*}{ p-value ${ }^{(2)}$} & \multirow{2}{*}{ p-value ${ }^{(3)}$} \\
\hline & $n=145$ & $\%$ & $n=143$ & $\%$ & & $n=154$ & $\%$ & & \\
\hline \multicolumn{10}{|l|}{ Purpose of use of the internet } \\
\hline Watching online videos & 96 & 66.2 & 100 & 69.9 & 0.804 & 102 & 66.2 & 0.775 & 0.589 \\
\hline Social game & 37 & 25.5 & 49 & 34.3 & 0.151 & 45 & 29.2 & 0.549 & 0.386 \\
\hline Online game & 29 & 20.0 & 23 & 16.1 & 0.313 & 32 & 20.8 & 0.947 & 0.274 \\
\hline Looking at social media & 68 & 46.9 & 73 & 51.0 & 0.677 & 61 & 39.6 & 0.142 & 0.058 \\
\hline Posting on social media & 21 & 14.5 & 24 & 16.8 & 0.682 & 16 & 10.4 & 0.249 & 0.116 \\
\hline Communication by email or LINE & 124 & 85.5 & 129 & 90.2 & 0.639 & 136 & 88.3 & 0.816 & 0.806 \\
\hline Information search & 90 & 62.1 & 96 & 67.1 & 0.611 & 88 & 57.1 & 0.253 & 0.096 \\
\hline Use of apps & 77 & 53.1 & 81 & 56.6 & 0.781 & 77 & 50.0 & 0.448 & 0.295 \\
\hline Others & 3 & 2.1 & 0 & 0 & & 0 & 0 & & \\
\hline No response & 7 & 4.8 & 2 & 1.4 & & 4 & 2.6 & & \\
\hline
\end{tabular}

${ }^{(1)}$ Migraine vs Other headache, ${ }^{(2)}$ Migraine vs No headache, ${ }^{(3)}$ Other headache vs No headache

Table 4. Internet addiction and purpose of use of the internet

\section{Discussion}

\section{Current status of headache}

In our previous study, the prevalence rate of headache among pharmacy students was $28.3 \%$ [4]. The prevalence of migraine in this study was $32.8 \%$, and the prevalence among female students was $36.8 \%$ (129/351 students). Although the prevalence rate among 20 year olds in the Japanese epidemiological survey was $12.9 \%$ [3], the prevalence of migraine among pharmacy students may be high because of the high percentage of females. Moreover, it was found that migraine has a significantly larger influence on sleep deprivation, daily life, and leaning than other headaches. Seizure inducing factors are observed in approximately $75.0 \%$ of migraine patients [13]. In this study, we confirmed that students with migraine had triggers such as sleep disorder (62.1\%) and stress (56.6\%). Not only headache, but also accompanying symptoms, are known to affect the quality of life of migraine patients [1-4]. Indeed, accompanying symptoms, such as headache exacerbation during daily activities, nausea, photophobia, osmophobia and phonophobia, were observed more in students with migraine than in those with other headaches. Thus, students with migraine in this study had characteristics of general migraine patients.

\section{Relationship between migraine and internet addiction}

According to the YIAT, the migraine group had significantly more students with IA than the other headache and no headache groups. According to Katayama and Mizuno-Matsumoto, 58\% of university students were Internet-dependent, and $7.6 \%$ of students have a considerably high reliance on the Internet [6]. In our present study, $60.7 \%$ of students in the migraine group had possible IA (moderate risk) or IA (high risk) and $7.6 \%$ had IA. On the other hand, the percentages of those with possible IA and IA in the other headache and no headache groups were $47.6 \%$ and $45.5 \%$, respectively. As the IA score was higher in the migraine group, IA may be related to the pathogenesis of migraine in pharmacy students. Although there was a significant difference in the IA score among these groups, there was no significant difference in the net usage time during the day. In our study, usage time of the Internet was not defined. Therefore, the definition of
Internet use may have differed among individuals.

There are several reasons as to why the migraine group had a higher degree of Internet dependence than the other groups. First, it is possible that sleep deprivation due to excessive use of the Internet causes migraines because $62.1 \%$ of students with migraines stated sleep problems (lack of sleep and excess sleep) as a trigger of headache. Six students among 11 students with IA in the migraine group had sleep problems (data not shown). Moreover, as students in the migraine group (31.7\%) had sleep deprivation due to headache, lack of sleep due to IA may induce headaches, thereby exacerbating sleep deprivation. Second, psychiatric disorders, such as depression and anxiety disorder, may be involved with IA in students with migraines. Persons with Internet or smartphone addiction have a significantly higher risk of depression and anxiety disorder than those without Internet or smartphone addiction [14]. Ha et al. also reported a significant association between IA and depressive symptoms in adolescents [8]. In addition, migraine patients have a high risk of depression and anxiety disorder $[15,16]$. Moreover, psychiatric disorders[17] and stress are risk factors for aggravation of migraine headaches [18]. We also confirmed that migraines are aggravated by depression [7]. Therefore, the pathologies of IA and migraine may be similar.

The amounts of striatal dopamine transporter [19] and dopamine D2 receptors [20] are known to be lower in people with IA. Moreover, Liu and Luo found that the peripheral blood plasma dopamine level in individuals with IA was significantly higher than that in the control group [21]. On the other hand, high dopamine levels in platelets have been observed in migraine patients without aura [22]. Migraines are known to develop in patients without aura [7,23]. In the present study, 10 students among 11 with IA in the migraine group had migraine without aura (data not shown). In addition, the increased dopamine release from the brain was suggested to be involved in the transformation of migraine to medication overuse headache $(\mathrm{MOH})$ [24]. We previously reported that dopamine receptor 2 (DRD2) C939T (rs6275) is involved in $\mathrm{MOH}$ complication in migraine patients [7]. Therefore, Internet activities may stimulate dopamine release in students with migraine, resulting in IA. Alternatively, IA may stimulate dopamine release, leading to migraine. 
The sample size and limited subjects (pharmacy students) are the limitations of this study. In addition, there is a possibility that the other headache group included those with migraine because a headache specialist was not consulted. However, we revealed that students with migraine are significantly more dependent on the Internet than those in the other headache and no headache groups. It is important to teach about the effects of IA on lifestyle, physical and mental health, and that less Internet use may suppress the development of migraines.

\section{Acknowledgements}

We thank Hazuki Shimode, a student at the Showa University School of Pharmacy, for her technical assistance. The authors would like to thank Medical English Service (https://www.med-english.com/) for the English language review.

\section{Conflict of interest}

\section{None}

\section{References}

1. Takeshima T, Ishizaki K, Fukuhara Y, et al. Population-based door-to-door survey of migraine in Japan: the Daisen study. Headache. 2004;44:8-19.

2. Ishii $M$, Sakairi $Y, H a r a ~ H$, et al. Negative predictors of clinical response to triptans in patients with migraine. Neurol Sci. 2012;33:453-461.

3. Sakai $F$, Igarashi $H$. Prevalence of migraine in Japan: a nationwide survey. Cephalalgia. 1997;17:15-22.

4. Hirano $T$, Ishii $M$, Ishibashi $M$, et al. Investigation of understanding and responding to headaches for pharmacy students. J Community Pharm Pharm Sci. 2018;10:185194. [text in Japanese with English abstract].

5. Kim BS, Chang SM, Park JE, et al. Prevalence, correlates, psychiatric comorbidities, and suicidality in population with problematic Internet use. Psychiatry Res. 2016;244:249-256.

6. Katayama $Y$, Mizuno-Matsumoto $Y$. Internet dependence tendency in university students and its impact on their health and lifestyle performance. HEP. 2016;43:657-64. [text in Japanese with English abstract].
7. Onaya $\mathrm{T}$, Ishii $\mathrm{M}$, Katoh $\mathrm{H}$, et al. Predictive index for the onset of medication overuse headache in migraine patients. Neurol Sci. 2013;34:85-92.

8. $\mathrm{Ha} \mathrm{JH}$, Kim SY, Bae SC, et al. Depression and Internet addiction in adolescents. Psychopathology. 2007;40:424-430.

9. Cerutti R, Presaghi F, Spensieri V, et al. The potential impact of internet and mobile use on headache and other somatic symptoms in adolescence. A populationbased cross-sectional study. Headache. 2016;56:1161-1170.

10. Lipton RB, Dodick D, Sadovsky R, et al. A self-administered screener for migraine in primary care. The ID MigraineTM validation study. Neurology. 2003;61:375-382.

11. Headache Classification Committee of the International Headache Society (HIS): The International Classification of Headache Disorders, 3rd. edition. Cephalalgia. 2013;33:629-808.

12. Young KS. Caught in the net: How to recognize the signs of internet addiction-and a winning strategy for recovery. New York: John Wiley \& Sons. 1998.

13. Kelman L. The triggers or precipitants of the acute migraine attack. Cephalalgia. 2007;27:394-402.

14. Kim YJ, Jang HM, Lee $Y$, et al. Effects of internet and smartphone addictions on depression and anxiety based on propensity score matching analysis. Int J Environ Res Public Health. 2018;15:859.

15. Antonaci F, Nappi G, Galli F, et al. Migraine and psychiatric comorbidity: a review of clinical findings. J Headache Pain. 2011;12:115-125.

16. Rist $\mathrm{PM}$, Schurks $\mathrm{M}$, Buring JE, et al. Migraine, headache, and the risk of depression: prospective cohort study. Cephalalgia. 2013;33:1017-1025.

17. Ferrari $A$, Leone $S$, Vergoni $A V$, et al. Similarities and differences between chronic migraine and episodic migraine. Headache. 2007:47:65-72.

18. Fanciullacci M, De Cesaris F. Preventing chronicity of migraine. J Headache Pain 2005; 6: 331-333.

19. Hou H, Jia S, Hu S, et al. Reduced striatal dopamine transporters in people with internet addiction disorder. J Biomed Biotechnol. 2012;2012:854524.

20. Kim SH, Baik SH, Park CS, et al. Reduced striatal dopamine D2 receptors in people with Internet addiction. Neuroreport. 2011;22:407-411.

21. Liu M, Luo J. Relationship between peripheral blood dopamine level and internet addiction disorder in adolescents: a pilot study. Int J Clin Exp Med. 2015;8:9943.

22. D'Andrea G, Granella F, Perini F, et al. Platelet levels of dopamine are increase in migraine and cluster headache. Headache. 2006;46:585-591.

23. Headache Classification Committee, Olesen J, Bousser MG, Diener HC, et al. New appendix criteria open for a broader concept of chronic migraine. Cephalalgia. 2006:26:742-746.

24. Calabresi P, Cupini LM. Medication-overuse headache: similarities with drug addiction. Trends Pharmacol Sci. 2005;26:62-68. 